\title{
Correction to: Orthodontic treatment of the transposition of a maxillary canine and a first premolar: a case report
}

\author{
Maria Teresa Dinoi ${ }^{* *}$, Stefano Mummolo ${ }^{1}$, Annalisa Monaco ${ }^{1}$, Enrico Marchetti', Vincenzo Campanella ${ }^{2}$ and
} Giuseppe Marzo ${ }^{1}$

\section{Correction: J Med Case Reports (2015) 9: 48 \\ https://doi.org/10.1186/s13256-015-0521-z}

In the publication of this article [1], there is an error in the Family Name and Given Name of the authors since these were interchanged.

The error:

Dinoi Maria Teresa ${ }^{*}$, Mummolo Stefano ${ }^{1}$, Monaco Annalisa $^{1}$, Marchetti Enrico ${ }^{1}$, Campanella Vincenzo ${ }^{2}$ and Marzo Giuseppe ${ }^{1}$

Should instead read:

Maria Teresa Dinoi ${ }^{1 *}$, Stefano Mummolo ${ }^{1}$, Annalisa Monaco $^{1}$, Enrico Marchetti ${ }^{1}$, Vincenzo Campanella ${ }^{2}$ and Giuseppe Marzo ${ }^{1}$

This has now been included in this correction.

\section{Author details}

'Department MeSVA, School of Dentistry, University of L'Aquila, L'Aquila, Italy.

${ }^{2}$ Department of Clinical Science and Translational Medicine, University of

Rome "Tor Vergata", Rome, Italy.

Received: 8 January 2019 Accepted: 8 January 2019

Published online: 04 March 2019

\section{Reference}

1. Teresa DM, Stefano M, Annalisa M, et al. Orthodontic treatment of the transposition of a maxillary canine and a first premolar: a case report. J Med Case Rep. 2015;9:48. https://doi.org/10.1186/s13256-015-0521-z.

\footnotetext{
* Correspondence: teresadinoi@hotmail.it

'Department MeSVA, School of Dentistry, University of L'Aquila, L'Aquila, Italy Full list of author information is available at the end of the article
} 